\title{
Botanical Based Safe and Nontoxic Mosquito Impregnated Gel
}

Nusrat Iqbal ․, Natish Kumar, Amrish Agrawal, Jitendra Kumar

Institute of Pesticide Formulation Technology, Ministry of Chemicals and Fertilizer, Govt. of India Sec-20, UdyogVihar, Gurugram-122016, Haryana, India

- Corresponding author email: nusratsiddiqa20@gmail.com

Journal of Mosquito Research, 2019, Vol.9, No.3 doi: 10.5376/jmr.2019.09.0003

Received: 06 Mar., 2019

Accepted: 28 May, 2019

Published: 16 Aug., 2019

Copyright $\odot 2019$ Iqbal et al., This is an open access article published under the terms of the Creative Commons Attribution License, which permits unrestricted use, distribution, and reproduction in any medium, provided the original work is properly cited.

Preferred citation for this article:

Iqbal N., Kumar N., Agrawal A., and Kumar J., 2019, Botanical based safe and nontoxic mosquito impregnated gel, Journal of Mosquito Research, 9(3): 18-24(doi: $\underline{10.5376 / \mathrm{jmr} .2019 .09 .0003}$ )

\begin{abstract}
Mosquito problem is the major problem in our country. There are many pesticide formulated products available in the market to compete the mosquito generating problems. The major drawback of these products is that they are not safe for human beings so, there is urgent requirement of safe and effective formulation. The aim of this study is to develop an effective, safe, and slow release formulation against mosquito control. In the present study, neemmicroemulsion was converted into microemulsion gel by using polymeric gel matrix Carbopol-934. Microemulsion formulation is the thermodynamically stabilized formulation and globular size is in nano range. These characteristic features of microemulsion will remain same in the gel phase. Size and zeta potential of microemulsion gel are $(400 \pm 6) \mathrm{nm}$ and $-10.0 \mathrm{~m} \mathrm{~V}$, respectively. Synersis, spreading coefficient value are in the range of stabilized gel formulation and suitable for impregnating mosquito net. Neemmicroemulsion based gel impregnated net gives $90 \%$ repellency against mosquitoes.
\end{abstract}

Keywords Microemulsion; Impregnated net; Spreading and repellency

\section{Background}

Mosquito problem are the main causative agents for many dangerous diseases that will threaten productivity and economy development of any country. Mosquitoes are the most favorable vector for the transmission of different destructive diseases (Lengeler, 2004). In every 10 years, mosquito transmits anew pathogen for new disease and sudden occurrence will cause serious and unmanageable problems.

There are various mosquito control insecticide formulations available in the market like mosquito coil, cream, aerosol sprays etc.. These formulations have been effectively controlled the mosquito problem since many years but recently some acute and chronic problems are seeing in human beings. Insecticide treated Nets (ITN) can significantly reduce the individual direct exposure risk to harmful insecticides and effectively decrease the transmission of mosquito borne diseases (Howard et al., 2000). ITN are not only create physical barrier from mosquito biting, but also give prolonged duration competence by means of killing and repellency of mosquito species.

ITN are most commonly impregnated by Permethrin and Piperonyl Butoxide pesticides, but these pesticides prenatal exposure cause lowering the mental development of the children (Megan et al., 2011). Many studies reveals that Permethrin are also responsible for endocrine disruption of human beings (Kabir et al., 2015). The toxic effect to human beings can be reduced by introduction of plant based mosquito repellent for impregnating mosquito nets. These nets will be non-toxic in all respect like inhalation, ingestion, or direct contact to skin or eye.

Present study is based on impregnation of mosquito net by polymeric encapsulated neemnanogel for prolonged repellency towards mosquito species.

\section{Results and Discussion}

\subsection{Microemulsion size, zeta potential and Poly- dispersive index}

Microemulsion thermodynamic stability is mainly depending upon the globular size in the nano range. Zeta sizer is mainly used for the measurement of globular size of Microemulsion. Neem ME mean globular size was (200 \pm 4 ) $\mathrm{nm}$ and size of neem ME based gel is $(400 \pm 6) \mathrm{nm}$. The increased size in gel might be due to gelling matrix 
carbopol. Polydispersive values were measured as 0.23 , low value signifies that dispersion of neem oil is homogenously distributed in the ME formulation (Moghimipour et al., 2013).

Zeta potential reading of micro emulsion and micro emulsion gel was $-(10.2 \pm 4) \mathrm{m} \mathrm{V}$ and $-10.0 \mathrm{~m} \mathrm{~V}$ respectively. Higher negative values indicate that the micro emulsion gel is stabilized formulation.

\subsection{Phase separation}

Micro emulsion is the thermodynamically stable system so even after centrifugation no phase separation was seen as commonly occurs in emulsion system (unstable system). Hence, no separation further confirms that the system is highly stabilized.

There was no any phase separation was seen on micro emulsion system and after dilution with water it remains a homogenous stable system. Any type of crystallization was not observed even after extended period of storage.

\subsection{Physical appearance}

Neemmicroemulsion gel was off white coloured creamy, smooth in texture and glistening appearance and homogenous and uniformly mixed.

\section{$1.4 \mathrm{pH}$ value}

$\mathrm{pH}$ was very important for stability of the active ingredient in microemulsion system. When any formulstion which is alkaline or acidic in $\mathrm{pH}$ more chance of the degradation of the active ingredient. Microemulsion gel $\mathrm{pH}$ was record 6.8 i.e neutral it incanted that the active content is stable in the microemulsion gel formulation.

\subsection{Viscosity}

Viscosity is very important factor for easy spreading of the gel formulation. Viscosity of the neem ME gel was 24.76 Pa s due to gelling matrix cabopol (Chen et al., 2006).

\subsection{Syneresis test}

Syneresis is related to the structure and compaction of the gel which is controlled by the polymeric matrix. Syneresis results from the contraction of the gel without undergoing any evaporation of the fluid in microemulsion. This process occurs due to inter attractive forces of the gel matrix and direct the gel permeability and viscosity change due to gel compaction (Dewhurst et al., 1999). Syneresis was calculated by above mentioned formula and it was only $1 \%$ which mean compaction was more due to the inter attractive forces between Neem ME and polymeric gelling matrix carbopol.

\subsection{Spread ability}

Spread ability is the measure of lubricity directly related to friction coefficient. Rate of spreading depends upon viscosity, type of solvent used volatile or non-volatile in the formulation system (Duggin, 1996). When a gel takes less time to spread it means the gel has high spreadability and viscosity (Dantas et al., 2016).Uniform application of the gel formulation is highly depends upon the good spreadability and ideal for impregnation for any surface like mosquito net impregnation, dress impregnation etc., and give good activity against mosquito attack.

The microemulsion based gel formulation showed slight variation in spreadability values during storage at various conditions i.e. 0 degree, 54 degrees and 26 degrees. The spread ability of the neem microemulsion showed slight variation and acceptable limits during storage (Table 1).

Table 1 Spread ability of neem based microemulsion gel

\begin{tabular}{llll}
\hline Temperature & $0{ }^{\circ} \mathrm{C}$ & $54^{\circ} \mathrm{C}$ & $25^{\circ} \mathrm{C}$ \\
\hline Spreading coefficient (gm.cm/sec.) & $15.16 \pm 0.19$ & $14.65 \pm 0.33$ & $12.34 \pm 0.22$ \\
\hline
\end{tabular}

Note: Results expressed as relative std. deviation (RSD) significant differences $(p<0.05)($ mean \pm S.D, $\mathrm{n}=3)$

Variation in temperature condition slightly changes the spread ability coefficient. In pure neem based gel by viscosity is fluctuated in different temperature conditions due to fatty acid contents and changed the spread ability beyond the acceptable limits and results into unstable gel formulation. This problem is successfully overcome in 
Neem ME. In Neem ME, Surfactants and co surfactants was added and results into uniform spread ability at various temperature condition (Fontana et al., 2011).

\subsection{Neem oil content}

The uv- vis \% transmittance was remain the same i.e. $98.63 \pm 1.36 \%$ inmicroemulsion gel as in microemulsion system. This shows that there was no degradation of the active ingredient during transformation to micro emulsion gel.

\subsection{Release of active ingredient}

The release of the active ingredient from the gel has good linearity as compared to microemulsion system. In gel, active ingredient rate of diffusion over period of time is constant and start decreasing gradually but in microemulsion rate of release is gradually decrease day by day. Rate of release suggested that the drier the impregnation with thick film shows extended period of activity against mosquito. By addition of carbopol act as thickener as well as gelling matrix which enhance the activity of neem microemulsion (Aiyalu et al., 2016).

Percentage release was maximum up to initial 10 days then it was constant up to 20 days (Table 2).

Table 2 Percentage release of azadirachtin from neem formulation from the initial concentration

\begin{tabular}{llllll}
\hline $0 \mathrm{~d}$ & $2 \mathrm{~d}$ & $4 \mathrm{~d}$ & $6 \mathrm{~d}$ & $8 \mathrm{~d}$ & $10 \mathrm{~d}$ \\
\hline $10 \%$ & $25 \%$ & $40 \%$ & $45 \%$ & $55 \%$ & $58 \%$ \\
\hline
\end{tabular}

\subsection{Accelerated stability studies}

Accelerated Stability testing of the gel at $54^{\circ} \mathrm{C}$ for 14 days demonstrate that the ME based microemulsion gel formulation physical appearance, viscosity, Syneresis remain same after 14 days storage period. Spreadability of the formulation remain same and uniform as freshly prepared gel. After storage $\mathrm{p} \mathrm{H}$ values remain same as before i.e. 6.5-6.8. No significant change in active ingredient content analysis by HPLC remains same after 14 days storage period.

\subsection{Repellency test of mosquito on neem microemulsion gel impregnatednet}

Repellency test was performed to evaluate repellency of mosquito against microemulsion based impregnated gel. Two sides of cage were hanged by treated net of dimensions $25 \times 25 \times 25 \mathrm{~cm}$ and two sides were left untreated and one upper side left for observing the repellency behavior of the mosquitoes. Mosquitoes were starved for four hours before exposing into the cage. 50 mosquitoes were put into the cage. Experiment of repellency was done in triplicates: three cages and each cage supplied with 50 mosquitoes. Observations were taken in every 10 minutes interval for $1 \mathrm{~h}$ (Table 3; Table 4; Figure 1; Figure 2).

Table $3 \%$ repellency against mosquito up to $1 \mathrm{~h}$ after spraying of microemulsion on mosquito net

\begin{tabular}{llllllll}
\hline Mosquito Behavior & $0 \mathrm{~min}$ & $5 \mathrm{~min}$ & $10 \mathrm{~min}$ & $15 \mathrm{~min}$ & $30 \mathrm{~min}$ & $45 \mathrm{~min}$ & $60 \mathrm{~min}$ \\
\hline Landing (\%) & 67.5 & 55 & 42.5 & 30 & 20 & 15 & 7.5 \\
Repellency (\%) & 32.5 & 45 & 57.5 & 70 & 80 & 85 & 92.5 \\
\hline
\end{tabular}

Table $4 \%$ repellency against mosquito of neemmicroemulsion gel up to $1 \mathrm{~h}$ after spraying on mosquito net

\begin{tabular}{llllllll}
\hline Mosquito Behavior & $0 \mathrm{~min}$ & $5 \mathrm{~min}$ & $10 \mathrm{~min}$ & $15 \mathrm{~min}$ & $30 \mathrm{~min}$ & $45 \mathrm{~min}$ & $60 \mathrm{~min}$ \\
\hline Landing (\%) & 50 & 30 & 25 & 12.5 & 2.5 & 0 & 0 \\
Repellency (\%) & 50 & 70 & 75 & 87.5 & 97.5 & 99 & 99 \\
\hline
\end{tabular}

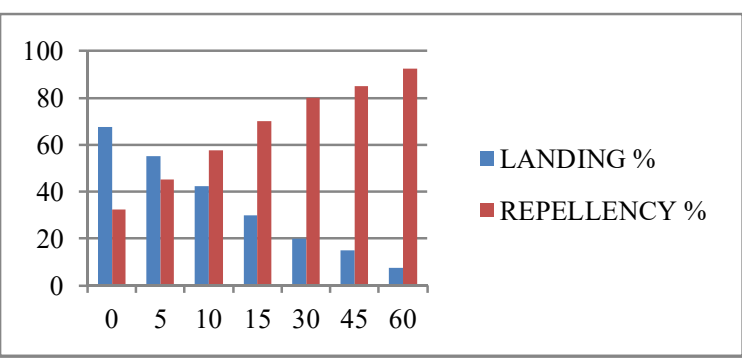

Figure 1 Mosquito behavior after $1 \mathrm{hr}$ on microemulsion sprayed net 


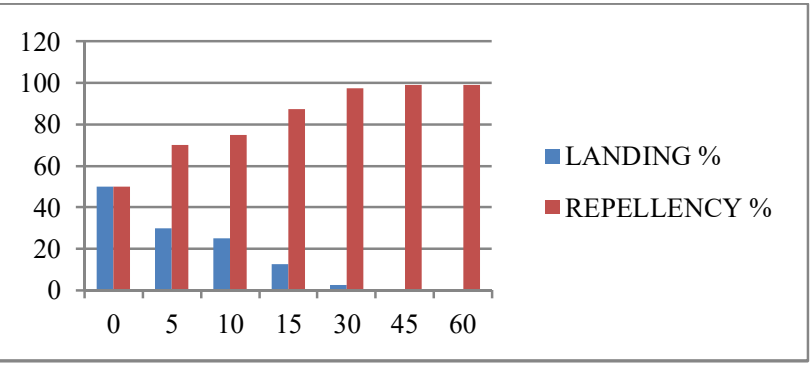

Figure 2 Mosquito behavior after $1 \mathrm{hr}$ on neem micro emulsion based gel sprayed net

Mosquito repellency was calculated by following formula (Table 5; Figure 3):

Mosquito Repellency $(\%)=$ No. of mosquitoes landing on treated net/ Total no. of mosquitoes in the cage $\times 100$

Neemmicroemulsion is the stable isotropic solution. When it was spreaded on the mosquito net it was uniformly dispersed over the net, but persistence is not as in neem based microemulsion gel. Neemmicroemulsion gel is encapsulated in the polymeric coating so the effectiveness against the mosquito up to prolonged period of time in comparison to microemulsionspray.

Table 5 Comparison of \% repellency of microemulsion and microemulsion

\begin{tabular}{lll}
\hline Microemulsion gel -impregnated net & $\begin{array}{l}\text { Mosquito Repellency }(\%)=\text { No. of mosquitoes landing on treated net/ Total no. of } \\
\text { mosquitoes in the cage } \times 100\end{array}$ \\
\hline Time period & Total no. of mosquitoes & \% repellency \\
$0 \mathrm{~h}$ & 10 & 92 \\
$2 \mathrm{~h}$ & 10 & 70 \\
$3 \mathrm{~h}$ & 10 & 50 \\
$5 \mathrm{~h}$ & 10 & 20 \\
Microemulsion- Impregnated net & & 99 \\
$0 \mathrm{~h}$ & 10 & 89 \\
$2 \mathrm{~h}$ & 10 & 75 \\
$3 \mathrm{~h}$ & 10 & 50 \\
$5 \mathrm{~h}$ & 10 & 99 \\
\hline
\end{tabular}

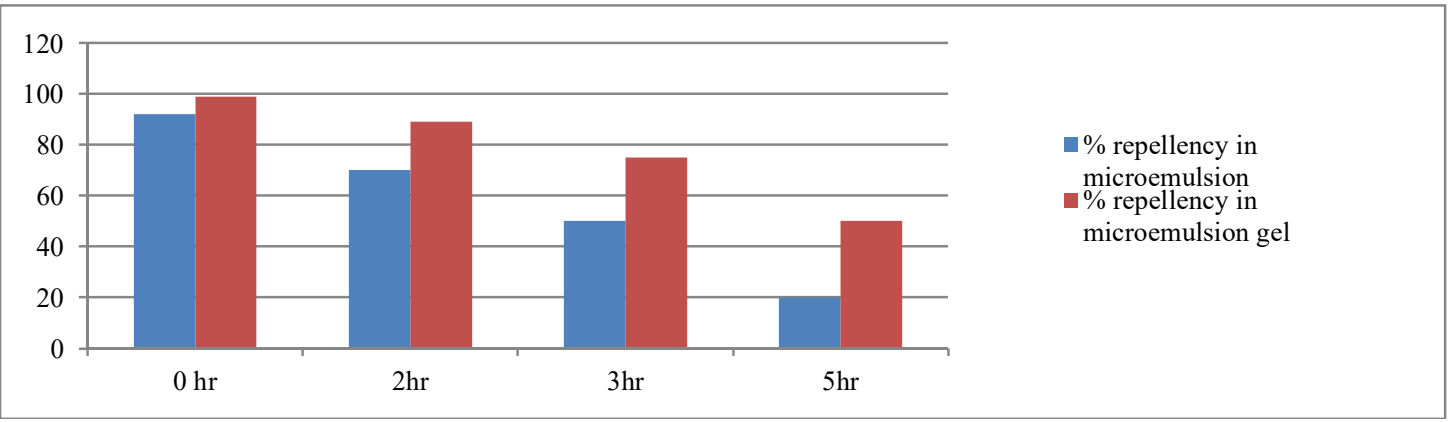

Figure 3 Mosquito behavior on neem gel impregnated net up to $5 \mathrm{~h}$

\section{Materials and Methods}

Neem oil, Tween 80, lemon grass, Butanol, Carbopol, Triethylamine.

\subsection{Preparation method of microemulsion}

Microemulsion was prepared by adding oil phase with the help of dropper in aqueous phase under continuous stirring at $200 \mathrm{rpm}$. Aqueous phase contain $10 \mathrm{~g}$ of surfactant mixer in a 3: 2 ratio (Tween 80: Span 30), but anol 2 $\mathrm{g}$, polyethylene glycol $1.5 \mathrm{~g}$ and $30 \mathrm{~g}$ water. Oil phase contain neem oil with lemon grass oil in 3:1 ratio. After adding oil phase the resultant emulsion solution was left for stirring on $200 \mathrm{rpm}$ up to $1 \mathrm{~h}$ at room temperature. After homogenously mixing the two phases, final microemulsion solution was transparent in physical appearance. 


\subsection{Preparation method of microemulsion gel}

Carbopol-934 was selected as gel matrix. 1g of carpool -934 was mixed in distilled water and left for swelling upto $1 \mathrm{~h}$. Microemulsion was added in swollen carpool solution and mix homogenously. After complete mixing of microemulsion and carbopol, $10 \mathrm{~g}$ polyethylene glycol and $0.5 \mathrm{~g}$ of triethylamine was added drop wise to neutralize the acid residues due to carbopol. After addition of all the ingredients, the mixer was stirred vigorously by a glass rod till the stable gel formed.

\subsection{Estimation of microemulsion stability}

\subsubsection{Globular size and zeta potential determination}

The globular size and zeta potential determinations were done by Zetasizer (Malvern instrument). All the measurement was done at $25^{\circ} \mathrm{C} .1 \mathrm{ml}$ of sample was diluted with distilled water (Graf et al., 2009). All the measurement was done in triplicates.

\subsubsection{Phase separation}

Phase separation was checked by centrifugation at 15,000 rpm for 30 minutes (Yogeshwar et al., 2009).

\subsection{Estimation of microemulsion based gel Physic-chemical analysis}

\subsubsection{Physical appearance}

The microemulsion gel was examined visually for their appearance, color etc. Stability of gel was also observed by physical appearance of stable homogenous gel structure without any separation of oil and water phases.

\subsection{2 $\mathrm{pH}$ determination}

The $\mathrm{Ph}$ of the microemulsion gel was checked by the Ph meter. For measuring $\mathrm{p} \mathrm{H} 1 \mathrm{ml}$ sample was diluted with distilled water and then $\mathrm{Ph}$ reading was taken at room temperature. All the measurements were done in triplicates (Bhanu et al., 2011).

\subsubsection{Viscosity determination}

Viscosity was determined at ambient temperature by Brookfield digital viscometer(S-62, model LVDV-E) with a viscometer having spindle rotating at $12 \mathrm{rpm}$ (Nayak et al., 2005).

\subsubsection{Syneresis test}

This test is for measurement of any shrinkage of gel. In this first gel was kept in plastic tubes with a perforated base which is enclosed with what man filter paper. These plastic tubes were then kept in centrifuge tubes and centrifuged at $1000 \mathrm{rpm}$ for 10 minutes. After centrifugation filter paper and plastic tube content was weighted and syneresis calculated as (Bhumika et al., 2017):

$\%$ Syneresis $=$ wt of filter paper after centrifugation- wt of filter paper before centrifugation $\mathrm{x} 100$

Total weight of gel before centrifugation

\subsubsection{Spread ability}

For spread ability determination, by placing gel formulation on one point of one slide and then put another slide over the placed gel in such a way that the gel was sandwiched between two slides. The upper slide was slightly pressed by $100 \mathrm{~g}$ wt to form a thin layer between slides. After this weight was removed and fixed on one place. After 5 minutes $20 \mathrm{~g}$ weight was tied on upper slide cautiously and separated away the upper slide upto a distance of $7.5 \mathrm{~cm}$ (length of slide). The same procedure was repeated 3 times (Jain and Neal, 2007). Then spreadibility was calculated by this equation:

$\mathrm{S}=\mathrm{mx} 1 / \mathrm{t}$

Where, S- spread ability, m- Tied weight $(20 \mathrm{~g}), 1$ - Glass slide length $(7.5 \mathrm{~cm})$, t- Time taken $(\mathrm{sec})$ to slip off the slide 


\subsubsection{Active ingredient determination}

Active ingredient was determined spectrophotometric ally by taking absorbance reading at $400 \mathrm{~nm}$. For absorbance measurement, $1 \mathrm{gm}$ of gel was dissolved in $100 \mathrm{ml}$ distilled water and left at room temperature for 5 hrs. The prepared dilution was filtered through filter paper and then absorbance was measured at 400nm along with blank sample.

\subsubsection{Accelerated temperature Stability test}

Neem oil loaded microemulsion gel was sealed in $15 \mathrm{~mL}$ glass vials and then stored at $54^{\circ} \mathrm{C}$ temperature for 14 days. Physical stability was estimated by visual assessment for physical alterations like oil or water separation or any precipitation. Chemical stability was evaluated by the absorbance measurement by UV- VIS spectrophotometer at $\lambda \max 400 \mathrm{~nm}$.

\subsection{Mosquito repellency}

\subsubsection{Procedure for impregnation of mosquito net with microemulsion gel formulation}

Four pieces of net having dimensions $30 \times 30 \mathrm{~cm}$ were taken. Apply the prepared micro emulsion gel over the net. After uniform application allowed the net at room temperature for complete drying. In the same way micro emulsion formulation sprayed over the net, this was taken as reference. Mosquito repellency was checked on gel impregnated net and micro emulsion sprayed net along with control (untreated net).

\subsubsection{Maintenance and rearing of mosquito culture}

Mosquito culture was maintained at temperature of $26^{\circ} \mathrm{C} \pm 3^{\circ} \mathrm{C}$ and $70 \% \sim 85 \%$ relative humidity. Mosquitoes were kept in the iron framed cage covered by cloth of dimensions $30 \mathrm{~cm} \times 30 \mathrm{~cm} \times 30 \mathrm{~cm}$. Mosquitoes were supplied by the $1 \%$ glucose solution as energy source and water wetted cotton balls were kept in the cage as water source to satisfy their thirst. For proper development of gravid female mosquitoes they were fed on rabbit blood. Water container was also kept in the cage for laying egg over water surface. The eggs were kept undisturbed up to $48 \mathrm{~h}$ and after that the hatching will start and then eggs were transferred in other bowls filled with fresh water and with corn powder in the form of tablets.

\section{Conclusion}

Mosquito is extremely severe problem in India and if the problem remains same it will be unmanageable problem in future years. Mosquito is a major problematic insect out of all the household insects. Mosquito is the causative agent of many diseases like dengue, malaria, chickengunia etc. There are many mosquito control products are available in the market, but no control method or product is available which is botanical based and would give extended release against mosquito. Pesticide Impregnated net are available in the market but major drawback of this impregnated net formulation is that it gives negative effect on the brain cells and cause many mental disorders in new born babies. The present study gives totally safe and efficient product against mosquitoes for prolonged period of time. Neem oil micro emulsion based gel is used for impregnation of mosquito net. Micro emulsion gel has particles in the nano range and has very good spreading coefficient which results a uniform dispersion over the net surface. Polymeric gel marix makes it sticky and controlled release profile for prolonged period effectiveness. This micro emulsion based gel is the advancement of the micro emulsion formulation. Micro emulsion based gel is the highly stabilized formulation and can be used for textile impregnation in future and would be as effective as synthetic pesticide impregnation.

\section{Authors' Contributions}

NI (corresponding author) prepared the protocol and draft the manuscript, NK perform experiments and bioefficacy studies, AA analyzed the studies, JK approved the final manuscript. All authors read and approved the final manuscript.

\section{References}

Aiyalu R., Govindarjan A., andRamasamy A., 2016,Formulation and evaluation of topical herbal gel for the treatment of arthritis in animal model, Brazilian Journal of Pharmaceutical Sciences, 52(3): 493-507 https://doi.org/10.1590/s1984-82502016000300015 PMid: 14685815 
Bhanu P.V., Shanmugam V., and Lakshmi P.K., 2011, Development and optimization of novel diclofenacemul gel for topical drug delivery, Pharmacie Globale, 9(2): $1-4$

Bhumika M. C., and Dr. Dhiren P.S., 2017, A Review on Microemulsion Based Gel: A Novel Approach for Enhancing Topical Delivery of Hydrophobic Drug, international jouranal of pharmacy and pharmaceutical research, Human, 8(4): 19-35

Chen Y., Evans J., and Laufer M.F., 2006, Horizontal and vertical transmission of viruses in the honey bee, Apismellifera, Journal of Invertebrate Pathology, 92(3): 152-159

https://doi.org/10.1016/j.jip.2006.03.010

PMid: 16793058

Dantas M.G.B., Reis S.A.G.B., Damasceno C.M.D., Rolim L.A., Rolim-Neto P.J., Carvalho F.O., Quintans-JuniorL.J., and Almeida J.R.G., 2016, Development and evaluation of stability of a gel formulation containing the monoterpeneborneol, The Scientific World Journal, 4: 1-4 https://doi.org/10.1155/2016/7394685 PMid:27247965 PMCid:PMC4876256

Dewhurst D.N., Cartwright J.A., and Lonergan L., 1999, The development of polygonal fault systems by syneresis of colloidal sediments, Marine and Petroleum Geology, 16(8): 793-810 https://doi.org/10.1016/S0264-8172(99)00035-5

Fontana M.C., Rezerac J.F.P., Coradini K.D., Leal B.R., and Beck R.C.R., 2011, Improved efficacy in the treatment of contact dermatitis in rats by a dermatological nanomedicine containing clobetasolpropionate, European Journal of Pharmaceutics and Biopharmaceutics, 79(2): 241-249 https://doi.org/10.1016/j.eipb.2011.05.002 PMid:21605671

Graf A., Rades T., and Hook S.M., 2009, Oral insulin delivery using nanoparticles based on microemulsions with different structure-types: optimization and in-vivo evaluation, European Journal of Pharmaceutical, Science 37(3): 53-61

Hantash B.M., Bedi V.P., Kapadia B., Rahman Z., Jiang K., Tanner H., and Zachary C.B., 2007, In vivo histological evaluation of a novel ablative fractional resurfacing device, Lasers in Surgery and Medicine, 39(2): 96-107

https://doi.org/10.1002/1sm.20468

PMid: 17311274

Horton M.K., Rundle A., Camann D.E., Barr D.B., Rauh V.A., and Whyatt R.M., 2011, Impact of prenatal exposure to piperonylbutoxide and permethrin on 36-month neurodevelopment, Pediatrics, 127(3): 699-706

https://doi.org/10.1542/peds.2010-0133

PMid:21300677 PMCid:PMC3065142

Howard S.C., Omumbo J., Nevill C., Some E.S., Donnelly C.A., and Snow R.W., 2000, Evidence for a mass community effect of insecticide-treated bed nets on the incidence of malaria on the Kenyan coast, Transactions of The Royal Society of Tropical Medicine and Hygiene, 94(4): 357-360 https://doi.org/10.1016/S0035-9203(00)90103-2

Jain S., and Neal R.M., 2007, Splitting and merging components of a nonconjugateDirichlet process mixture model, Bayesian Analysis, 2(3): 445-472 https://doi.org/10.1214/07-BA219

Kabir E.R., Rahman M.S., and RahmanI., 2015, A review on endocrine disruptors and their possible impacts on human health, Environmental Toxicology and Pharmacology, 40(1): 241-258

https://doi.org/10.1016/j.etap.2015.06.009

PMid:26164742

Keown P., Häyry P., Morris P., Stiller C., Barker C., Carr L., and Tapper E., 1996, A blinded, randomized clinical trial of mycophenolate mofetil for the prevention of acute rejection in cadaveric renal transplantation, Transplantation, 61(7): 1029-1037 https://doi.org/10.1097/00007890-199604150-00008

Killeen G.F., Smith T.A, Ferguson H.M., Mshinda H., Abdulla S., Lengeler C., and Kachur S.P., 2007, Preventing childhood malaria in Africa by protecting adults from mosquitoes with insecticide-treated nets PLoSMed, 4:e229

https://doi.org/10.1371/journal.pmed.0040229

PMid:17608562 PMCid:PMC1904465

Lengeler C., 2004, Insecticide-treated bed nets and curtains for preventing malaria, Cochrane Database Syst Rev1-4 https://doi.org/10.1002/14651858.CD000363.pub2 PMid: 15106149

Moghimipour E., Salami A., and Eftekhari S., 2013, Design and characterization of microemulsion systems for naproxen, Adv Pharm Bull, 3(1): 63-71

Musawenkosi L.H., MabasoB.S., and Christian L., 2004, Historical review of malarial control in southern African with emphasis on the use of indoor residual house-spraying, Tropical Medicine and International Health, 9(8): 846-856 https://doi.org/10.1111/j.1365-3156.2004.01263.x

Nayak S.H., Nakhat P.D., and Yeole P.G., 2005, Development and evaluation of cosmeceutical hair styling gels of ketoconazole, Indian J. Pharm. Sci., 67(2): 231-233

Yogeshwar G., Vandana B., and Patravale B., 2009, Microemulsion based vaginal gel of fluconazole: Formulation,in vitroandin vivoevaluation, International Journal of Pharmaceutics, 365(1-2): 175-179

https://doi.org/10.1016/j.ijpharm.2008.08.021 